\title{
INDONESIA EN 2018: TRAZANDO EL CURSO CONTINUO DE LA DEMOCRATIZACIÓN EN MEDIO DE DESASTRES NATURALES
}

\author{
Christopher Lundry \\ El Colegio de México
}

El año de 2018 estuvo lleno de acontecimientos en Indonesia, en los que la noticia dominante fue la próxima elección de 2019, prefigurada por las elecciones regionales en 2018. Los críticos de la administración presidencial de Joko Widodo han sido rápidos en denunciar algunas de sus políticas internas, como la de impulsar una justicia extra-judicial, vista como antidemocrática, que refleja un giro a la derecha antes de las elecciones. Su rival, Prawovo Subianto, aunque tiene una serie de problemas asociados con su trasfondo; conserva algún apoyo. Las redes sociales y el fenómeno de las "fake news" también se ciernen sobre las elecciones, aunque Indonesia está tratando de controlarlas.

El terrorismo también regresó a Indonesia con ataques en Surabaya seguidos de la incorporación de nuevas políticas para prevenir la violencia, con la inminente preocupación de los derechos humanos. Los desastres naturales golpearon a Indonesia repetidas veces, ocasionando la muerte de miles de ciudadanos además de interrogantes sobre el sistema de advertencia para emergencias. No obstante las preocupaciones sobre el papel de Indonesia en la Asociación de Naciones del Sudeste de Asia (ANSEA), los hechos muestran que la administración de Widodo pretende continuar sus lazos con esa organización. Sigue habiendo nerviosismo sobre la inquietante región de Papúa Occidental, donde se encuentra la mina Grasberg, el mayor contribuyente externo de la base tributaria indonesia, existe un movimiento separatista. Finalmente, después de esfuerzos draconianos para reducir o erradicar el terrorismo dirigido hacia los Juegos Asiáticos, finalmente éstos se desarrollaron sin problemas en Jakarta y Palembang. 


\section{ELECCIONES 2019}

Las elecciones regionales en Indonesia se consideran esenciales para pronosticar cómo serán las elecciones presidenciales de 2019, la pregunta inminente es si el resultado podría mostrar algún apoyo para Widodo que pudiera interpretarse como el impulso necesario para notificar su ingreso a la campaña presidencial. Los que lo dudaban fueron pronto silenciados: "Posisi Politik Jokowi Kian Kuat (La posición política de Jokowi es crecientemente fuerte)" es la nota destacada en los encabezados de la página principal del Koram Tempo, uno de los periódicos indonesios más respetados, el 29 de junio, en seguida de la elección (Puspitasari et al., 2018: 1). El comunicado iba acompañado de un dibujo de Jokowi, con las mangas remangadas, relajado y sonriendo en el sillón de su oficina (al tiempo en que se escribía este artículo, Jokowi tenía una ventaja de doble dígito en las encuestas).

Dos semanas más tarde Jokowi hizo el anuncio formal de su participación en las elecciones representando al PLDI (Partido para la Lucha por la Democracia Indonesia), y señaló como su candidato vicepresidencial al clérigo musulmán, de 75 años, Ma'ruf Amin. Después de especulaciones sobre si otros se unirían a la contienda, se supo que el único candidato que anunció su candidatura antes de la fecha límite fue el oponente de Jokowi en la contienda de 2014, Prabowo Subianto, de la coalición de Gerindra: el PMN (Partido del Mandato Nacional), el PD (El Partido Democrático), con Berkarya, y el PJP (El Partido de la Justicia Próspera). El candidato a la vicepresidencia de Prabowo será la Sandiaga Uno, el vicegobernador de Jakarta, un empresario que habría de acrecentar la aceptación de Prabowo, porque nació en Sumatra y tiene lazos con Sulawesi.

El PLDI es un partido secular que tiene sus raíces en el PDI de la era de Suharto. Después de que fueron asaltadas las oficinas del PDI, el 27 de julio de 1996, en un intento por sacar a Megawati Soekarnoputri, la rama reformista del partido compitió en las elecciones de 1999 tras la salida de Suharto. Megawwati fue electa para la vicepresidencia, y se convirtió en presidenta después de que Abdurahman Wahid fue obligado a dimitir en 2001. La elección de Ma'ruf Amin es probablemente un intento para debilitar la posición de Jorkowi entre los votantes de orientación islámica. El Partido Gerindra de Prabowo es un partido nacionalista secular conservador que ha puesto énfasis en la unidad nacional, aunque su coalición aglutina un conjunto de partidos. El PJP y el PMN son dos partidos de orientación islámica. Berkarya es nominalmente un partido de los trabajadores, pero es populista en su orientación e incluye 
en su plataforma propuestas extrañas, como cerrar las escuelas para que los niños puedan aprender desde sus casas vía internet. El líder del partido es Hutomo Mandala Putra, hijo del expresidente Suharto (conocido como Tommy Suharto), lo que explica sus preferencias por eliminar las elecciones gobernativas provinciales en favor de nombramientos presidenciales; como dice el dicho, la manzana no cae tan lejos del árbol. El PD es el partido secular del ex presidente Susilo Bambang Yhudoyono, quien, al igual que Probowo, fue general.

Aunque la victoria de Jokowi en 2014 con 53\% de la votación se consideró clara, Probowo afirmó que el resultado se debía a trampas, por lo que cuestionó todo el proceso y pidió nuevas votaciones en algunas áreas; finalmente se retiró. Su solicitud oficial para revocar la elección fue denegada por unanimidad por el Tribunal Supremo de Indonesia.

Los resultados de la elección de 2014 tendrán una enorme importancia en la siguiente campaña, ya que ambos candidatos conservan elementos controversiales en sus historias. Jokowi reinstituyó la pena de muerte y las ejecuciones, en su mayoría de extranjeros, que fueron incrementadas temporalmente después de que tomó posesión de su cargo (las ejecuciones han disminuido desde entonces). También incrementó las acciones contra los buques pesqueros extranjeros atrapados en aguas indonesias, incluida su voladura, una política que la ministra de Asuntos Marinos y Pesca, Susi Pudjiastuti, prometió continuar en una declaración que hizo en enero. Lo anterior ha ocasionado intervención de la marina china en algunos casos, y con ello incrementado la tensión, hasta que Indonesia volvió su atención hacia otros barcos de la ANSEA. Estos y otros incidentes causaron tensión en las relaciones exteriores de Indonesia, aunque aparentemente se han calmado las cosas.

\section{ASUNTOS DE POLÍTICA INTERNA}

Internamente Jokowi ha sido criticado por fracasar en cuanto a disminuir las tensiones étnicas y religiosas que apuntan hacia los grupos minoritarios, lo mismo que hacia los grupos de lesbianas y homosexuales. Aunque una ley propuesta para prohibir las relaciones sexuales fuera de matrimonio fracasó por un estrecho margen (5-4) en la Suprema Corte, en diciembre de 2017 continuaron los intentos serios por legislar acerca de la moral en Indonesia.

Mientras varios políticos debaten si todos los partidos apoyan los derechos del movimiento LGBT, los políticos que están incluidos en tal movimiento son víctimas de abusos. 
El Parlamento continúa debatiendo una ley que penaliza el comportamiento entre personas del mismo sexo, desde las relaciones sexuales hasta los besos en público; esto último es algo que ocurre en las manifestaciones de apoyo a los derechos LGBT.

Como era de esperarse, el PND y el PJP son los oponentes más pronunciados de los derechos de lesbianas y homosexuales (Kurnia y Noroyono, 2018); en particular, el compañero de campaña de Jokowi llamó a la criminalización de la homosexualidad. Tunggal Pawestri, una activista feminista, notó la conexión entre la legislación propuesta y las elecciones que vienen. Las leyes "son una manera de conseguir votos". Mucho de lo que se ha discutido "es sólo una forma de vender su propuesta" (Widianto, 2018). Los políticos están torciendo la lógica y la credulidad en su intento por criminalizar el comportamiento LGBT, argumentando que criminalizarlo protegerá a quienes forman parte de este movimiento, o que alimentar a sus hijos con fideos instantáneos los convertirá en homosexuales, o bien, haciéndose eco de mentiras propagadas durante mucho tiempo, que la homosexualidad es una importación corrupta desde el oeste. Algunos han pedido la pena de muerte. Las mujeres transexuales han sido detenidas y enviadas a "centros de rehabilitación", y los reincidentes han sido amenazados con ser encarcelados. En mayo, el término "del mismo sexo" se eliminó del proyecto de ley y se reemplazó por "indecente", aunque los activistas de derechos humanos continuaron condenando el proyecto de ley porque "indecente" no está claramente definido ("Gov’t proposes", 2018).

La moralidad sexual también es un tema entre la milicia y la policía. Aunque Indonesia está buscando más candidatos femeninos, el servicio requiere de una prueba "de virginidad" para todas las candidatas, que es esencialmente una violación física, para asegurar su moralidad. La prueba no tiene validez en términos científicos, y resulta más criticable ahora que sabe que pueden realizarla médicos hombres. Las candidatas lo consideran humillante, y muchas que consideran el servicio militar como una opción, no hacen su solicitud debido a que deben cubrir la prueba de virginidad. (Siddharta, 2018).

Jokowi también ha mostrado que sus esfuerzos son ineficaces en el combate a la corrupción, como los hechos por la Comisión para Erradicar la Corrupción (CEC). Su triunfo en 2014 se debió en parte a su apoyo al combate y exterminio de la corrupción, y a lo que había logrado al respecto en sus posiciones políticas anteriores. Es probable que haya encontrado, sin embargo, que como presidente se enfrenta al rechazo de figuras políticas 
atrincheradas, lo que puede significar que avanzar en políticas anticorrupción es más difícil de lo que esperaba.

Las controversias de Prodowo son quizá más serias. Cuando fue director de las Fuerzas Militares Estratégicas de Indonesia, durante su mandato secuestraron, torturaron y mataron a activistas prodemocracia en la crisis del país de 1998, que condujo a las reformas democráticas. Seguido de una investigación militar, Probowo admitió su culpabilidad y fue removido de la milicia. Desde entonces se ha concentrado en sus intereses políticos y de negocios.

No obstante su pasado, Probowo sigue siendo popular; el expresidente Susilo Bambang Yhudoyono le ha dado su apoyo para su candidatura, lo mismo que otros generales de la era de Suharto (Salna, 2018). Thomas Pepinksi, científico y político de Cornell University, lo atribuye al deseo de los indonesios de que prevalezca el "orden" y la "ley" (Pepinsky, 2017: 120-131). Además, tal parece que Jokowi intenta acercarse a este grupo, al declarar su aprecio por las políticas del presidente filipino Rodrigo Duterte, quien mató a traficantes y usuarios de drogas de manera extraoficial, rumiando si esas políticas se podían llevar a cabo en Indonesia. Los activistas de derechos humanos y prodemocracia en Indonesia están preocupados, pues la campaña de 2019 podría ser peligrosa. En otro llamado al populismo, Jokowi introdujo medidas para que los trabajadores extranjeros tomaran lecciones de lengua indonesia, si es que iban a permanecer en el país por más de seis meses. Aunque Jokowi ha revertido algunas de las leyes que son vistas como un obstáculo para la inversión extranjera, algunos piensan que este nuevo requisito simplemente los reemplazará y será un obstáculo y un medio para que los funcionarios busquen dinero a partir de la corrupción. Si la idea era limitar la inmigración ilegal, seguramente no tendrá efecto sobre los inmigrantes ilegales no registrados. En cambio las leyes parecen apuntar hacia los empleados de cuello blanco que están en el país legalmente.

Los asesinatos extrajudiciales y la tortura siguen siendo un problema delicado. En enero, la policía señaló a diez miembros del ejército indonesio (TNI) como sospechosos de la tortura y asesinato de La Gode en Ternate, al norte de Maluku. Poco después los residentes expresaron su apoyo al asesinato extrajudicial, manifestando que era un ladrón y que causaba problemas (Djailani, 2017). Finalmente once elementos de la milicia indonesia fueron acusados y enjuiciados por este hecho (Amar, 2018). En Aceh, donde la ley de shariah es 
sancionada por el Estado, grupos de vigilantes han estado llevando a cabo ataques en nombre de la religión. En abril, una pareja de jóvenes fue encontrada sola, en uno de los apartamentos de sus padres, lo que fue interpretado como una violación al khalwat o ley de reclusión. Un grupo de jóvenes iracundos los forzaron a entrar a la mezquita local, donde fueron sumergidos en aguas residuales. Los padres del joven fueron obligados a mudarse y a pagarle una oveja y un millón de rupias al jefe del pueblo por la vergüenza causada. Andreas Harsono, de Human Rights Watch, advirtió que Aceh se está convirtiendo en un "Estado vigilante" (Lamb, "vigilante" 2018).

Pero no es solamente en Aceh donde lo religioso justifica que la violencia extrajudicial sea perpetrada. El notorio Frente Pembela Islámico (Frente Islámico de Defensores) y su ala paramilitar, Laskar Pembela Islámico (Tropas de Defensores Islámicos: LPI), continúan maltratando y atacando a la gente, en ocasiones frente a la policía, en nombre de la moralidad. Sus víctimas incluyen a miembros de minorías religiosas, entre ellos la secta Ahmadiyah, que son vistos como infieles, lesbianas y homosexuales, todos sospechosos de "vicios" y de no ayunar y orar durante el mes sacro del Ramadán. En enero, los miembros de la LPI que realizaban misiones de "barrido" en busca de un vicio en Pamekesan, Madura, irrumpieron en la fiesta de cumpleaños de un niño y atacaron a personas. Ningún miembro de la LPI fue arrestado (“Indonesian Islamists," 2018).

El liderazgo de la LPI incluye a miembros de grupos gansteriles de la era Suharto que llevon a cabo la ejecución, extorsión y maltrato en nombre del gobierno, y se sospecha que lo siguen haciendo (Woodward, et al., 2018: 153-54; Azali, 2017: 3-6). Aunque son extremistas y considerados por muchos como terroristas, no defienden a Salafi ni a Wahhabi Islam, y al contrario de algunos informes, no están vinculados a otras redes extremistas islámicas, como Jamaah Ansharut Daulah (JAD) o el Estado Islámico. Tras el derrocamiento de Suharto, mantuvieron sus vínculos con el poder y la policía, aunque ahora afirman que representan valores religiosos. En un reciente viaje a Arabia Saudita, el compañero de carrera de Jokowi, Mar'uf, se dirigió al líder del FPI, Rizieq Shihab, quien se encontraba exiliado ahí mientras huía de los cargos de antipornografía en Yakarta desde mayo de 2017 (Wiwoho, 2018). Se informó que Rizieq había sobrepasado su visa y que estaba enfrentando problemas legales en Arabia Saudita, pero como los cargos en Indonesia contra él fueron retirados debido a pruebas insuficientes, está planeando regresar. 
Sin embargo, el FPI enfrentó el rechazo, En el norte de Kalimantan, en julio, los jóvenes locales de Dayak rodearon el aeropuerto después de que Ja'far Shodiq, el vicepresidente del FPI y otros miembros viajaron a Tarakan para inaugurar un nuevo capítulo del grupo de vigilantes. A los miembros del FPI no se les permitió salir del aeropuerto, más bien se les obligó a dar marcha atrás ("FPI, líderes", 2018). Sin embargo, un informe de Kathleen Azali, del Instituto Yusof Ishak en el ISEAS, Singapur, señaló que siempre que hubo una reacción violenta contra el FPI sólo sirvió para aumentar su popularidad y membresía, ya que lo describen como persecución y martirio (Azali, 2017: 3-4).

En julio, mientras Yakarta y Palembang se preparaban para los Juegos Asiáticos, el inspector general en jefe de la policía de Yakarta, Idham Azis, dio instrucciones a la policía para que disparara a los delincuentes a la vista ("Policía de Indonesia", 2018). Human Rights Watch emitió un informe en el que condenó esta política, señalando la conexión con los asesinatos "al estilo de Duterte" en Filipinas, una conexión que el jefe de la Agencia Nacional de Estupefacientes de Indonesia, el general Budi Waseso, estaba muy interesado en otorgar una opinión favorable (Kine, 2018). Budi también calificó las vidas de los traficantes de drogas como "sin sentido". En menos de dos semanas Amnistía Internacional informó que la policía había matado a docenas de personas y había herido a muchas más en Yakarta (Cordero, “policía”, 2018). En julio, el superintendente de policía de Bangka Belitung, M. Yusuf, fue captado por la cámara golpeando a una mujer y a un adolescente de 14 años sospechoso de robar en una tienda de su propiedad. En este caso el video se volvió viral y Yusuf fue despedido (Santoso, 2018).

Esta violencia está ocurriendo en el 20 aniversario del movimiento de reformas. El levantamiento contra Suharto también se dio durante un periodo de detención generalizada, tortura, violación y "desaparición" de activistas a favor de la democracia y de personas de etnia china. Un reciente informe del South China Morning Post examina a algunas de las víctimas de los ataques, señalando que Prabowo fue el responsable, y pregunta si se ha avanzado con reformasi (Yuniar y Hutton, 2018). Dada la continua violencia extrajudicial y el apoyo de parte del presidente, es una pregunta justa.

Aunque en 2019 se cumplen veinte años del inicio del proceso de democratización formal de Indonesia con las primeras elecciones libres desde 1955, la política nacional indonesia todavía tiende a basarse en personalidades y, en menor medida, en la maquinaria 
del partido, con pocas o ninguna diferencia política importante y concreta entre los candidatos. Yoes C. Kenawas y otros han advertido sobre el regreso de la política dinástica y la vuelta al autoritarismo (Kenawas, 2018).

\section{REDES SOCIALES Y "FAKE NEWS"}

Un elemento que sin duda afectará a las elecciones son las redes sociales, incluidas las campañas que intentan difundir desinformación o iniciar rumores sobre candidatos. En las elecciones de 2014, los usuarios de las redes sociales divulgaron que Jokowi era un cristiano con ascendencia china, aunque en realidad es musulmán con ascendencia javanesa. Ahora bien, aunque en un mundo perfecto la etnia y la religión de un candidato no deberían importar, pueden ser suficientes para influir en una elección cercana. El fenómeno no se limita a países en desarrollo como Indonesia; las recientes elecciones presidenciales en Estados Unidos con Barack Obama incluyeron campañas que cuestionaron su religión, ciudadanía y etnia; también, una investigación actual mostró que agentes rusos interfirieron en las campañas de medios en línea durante las elecciones presidenciales de 2016.

Las campañas en línea ciertamente afectaron el apoyo al exgobernador de Yakarta, Basuki “Ahok" Tjahaja Pernama, quien se rumorea que está atendiendo intereses chinos para socavar Indonesia; debido a ello, las campañas en línea contribuyeron a su arresto y juicio por blasfemia. Entre los grupos que patrocinan la propagación de rumores sobre Ahok se encuentran grupos extremistas islámicos, como el FPI y otros que simpatizan con asociaciones terroristas. Indudablemente intentarán hacer el mismo tipo de maquinaciones en la elección del siguiente año; han arrojado su peso detrás de Prabowo, y así, será Jokowi el que se enfrente a la peor parte de este tipo de ataques. Aún está por verse si serán efectivos o no, o si los indonesios los ignorarán o ridiculizarán, ya que Jokowi continúa siendo popular. Un ejemplo importante de noticias falsas sobre Jokowi que surgió en octubre es el siguiente: la legisladora Gerindra Rachel Maryam difundió imágenes de Ratna Sarumpaet, una famosa actriz, escritora, productora y directora indonesia, así como crítica vocal de Jokowi, en todo el ciberespacio. Las imágenes mostraban moretones en su rostro, y Maryam afirmó que Sarumpaet fue atacada el 21 de septiembre en Bandung. Los opositores de Jokowi se apresuraron a etiquetar el hecho como un ataque político; incluido el propio Prabowo, quien lo calificó como una violación a los derechos humanos. El 3 de octubre, sin embargo, surgió 
la verdad: Sarumpaet estaba en Yakarta el 21 de septiembre, y las contusiones se debieron a una cirugía plástica ("Misinformation “, 2018).

En un intento por frenar este tipo de rumores y falsedades, Jokowi ha apoyado una ley de "noticias falsas" en Indonesia (tal vez con algún interés propio, dados los rumores que giran sobre las elecciones de 2014). La campaña se dirigió al Ejército Cibernético Musulmán (MCA), un grupo responsable de difundir rumores sobre Ahok, entre otros. En marzo, las autoridades indonesias arrestaron a 14 miembros del MCA y han estado investigando cómo funciona su red, incluido el uso de bots o cuentas semiautomáticas. Como siempre, hay otro lado: los defensores de la ley y los defensores de la libertad de expresión se preocupan de que se utilice para silenciar a la disidencia o para crear una atmósfera tensa de comunicación política.

Las acusaciones de blasfemia, por ejemplo, se han utilizado para acallar a la oposición, y en regiones tranquilas, como Papúa Occidental, el discurso y el derecho de reunión se reducen frecuentemente con el pretexto de prevenir el terrorismo. Los críticos también señalan la dificultad de verificar la verdad objetiva, cuando a veces, como Rashomon, hay más de una perspectiva o interpretación de un evento. Los países vecinos, como Tailandia, Malasia y Filipinas, han promulgado leyes parecidas y tienen historias similares en contra de la disidencia.

\section{TERRORISMO}

El terrorismo irguió su horrible cabeza en Indonesia en 2018, con múltiples ataques efectuados en junio en Surabaya. Se dice que tres grupos de personas de la misma familia, incluidos el padre, la madre y los niños, se dirigieron a tres iglesias diferentes en Surabaya, donde en algún momento hubo actos de terrorismo. Sidney Jones, director del Instituto para el Análisis de Políticas de Conflicto en Yakarta, escribió en el New York Times que los ataques que se realizaron en Surabaya muestran una evolución en las tácticas de los terroristas internos: el hecho de incluir a mujeres y niños en los ataques, algo que se ve en conflictos en otros lugares, pero no antes en Indonesia. Jones señaló también que no todos los que apoyan al Estado islámico y están dispuestos a cometer actos de terrorismo son miembros del JAD, la red terrorista más grande de Indonesia (Jones, 2018). 
La organización terrorista regional Jemaah Islamiyah había dejado de promover ataques como éste después del bombardeo de Bali en 2002, aunque un grupo disidente liderado por Noordin Top continuó haciéndolo hasta su muerte en 2009. JAD, un grupo afiliado al Estado islámico, no tiene reparos sobre el uso de la violencia. Jones sostiene que estos ataques pueden ser un signo de debilidad y no de fuerza; sin embargo, el grupo fue declarado ilegal por un tribunal de Yakarta, y su líder, Aman Abdurrahman, condenado a muerte por su intervención en la coordinación de ataques terroristas anteriores. El grupo extremista Hizbut Tahrir Indonesia perdió una apelación en mayo luego de ser vetado el año pasado. El grupo había recorrido un área gris en Indonesia: abogaba por la sharia y por un califato local que está prohibido en varios países, pero en Indonesia fue tolerado durante muchos años debido a que rechazaba los métodos violentos. Una decisión judicial confirmó la prohibición por el hecho de que el grupo era anti-Pancasila, la ideología de cinco pilares del estado indonesio desde su fundación.

Luego del ataque a Surabaya, y con la asistencia de una ley antiterrorista reforzada que permite a la policía indonesia arrestar a personas hasta por 221 días simplemente por ser sospechosas de pertenecer a algún grupo terrorista, las autoridades encarcelaron a casi 50 personas en Yakarta por vínculos con el JAD (“50 arrested”, 2018). La policía indonesia también ha cerrado cerca de 3000 sitios web que fueron señalados como promotores del terrorismo, y está monitoreando a casi 10000 más.

Finalmente, los militares indonesios comenzarán a desempeñar un papel en los esfuerzos contra el terrorismo. Tras los atentados en Bali de 2003, la policía formó el Detasemen Khusus 88 (Destacamento Especial 88, Densus 88) en 2003 para combatir el terrorismo; dicho contraterrorismo quedó en manos de la policía. Con la formación del Kommand Operasi Khusus (Comando de Operaciones Especiales, o Koopsus), los militares también ejercerán un papel activo, aunque ha habido cierta oposición debido al pésimo historial militar en contra de los derechos humanos. Sin embargo, quizá más intrigante es la tensión que ha existido entre la policía y los militares desde 1999, cuando los dos grupos se separaron, seguidos por periódicos episodios de enfrentamientos violentos entre policía y militares, incluso sobre la jurisdicción, o los derechos de botín. En mayo, cuatro miembros del Densus 88 y un oficial de policía regular fueron asesinados cerca de Yakarta durante un motín en prisión. La prisión alberga a extremistas, y el Estado islámico se apresuró a anunciar 
su papel al respecto. Las autoridades indonesias, sin embargo, negaron el papel del Estado islámico.

Como reacción ante la amenaza interna del terrorismo este año, el Majelis Ulama Indonesia (Consejo de Ulama de Indonesia, MUI) creó un grupo islámico contra el terrorismo. $\mathrm{Su}$ objetivo era contrarrestar los mensajes radicales, con presencia en escuelas y universidades, así como en colaboración con organismos gubernamentales. Además de contrarrestar la ideología extremista, el grupo también pretende desmentir los rumores y la información falsa mediante las redes sociales (Epa, 2018).

El terrorismo es, pues, un aspecto de las relaciones exteriores que continúa estimulando la cooperación entre los estados de la ANSEA y sus vecinos. En enero de 2018, la Reunión de Ministros de Defensa de la ANSEA elaboró una declaración conjunta en la que se comprometió a mejorar la cooperación en los esfuerzos contra el terrorismo. En marzo firmó un memorando de entendimiento con Australia para mejorar sus esfuerzos con base en la Declaración Conjunta de Cooperación para Combatir el Terrorismo Internacional a partir de 2016. El ministro de Defensa de Indonesia, Ryamizard Ryacudu, enfatizó la importancia de los esfuerzos conjuntos contra el terrorismo en la XVII Cumbre de Seguridad de Asia, conocida como El Diálogo de Shangri La, en junio. Los estados miembros de la ANSEA, especialmente Malasia, Indonesia y Filipinas, desconfiaron del aumento del terrorismo luego de los seis meses de asedio a Marawi en el sur de Filipinas por parte de grupos terroristas, incluido Abu Sayyaf.

Los tres países acordaron cooperar con patrullas unificadas cerca de sus fronteras compartidas, y en abril, Indonesia y Singapur realizaron por primera vez ejercicios navales conjuntos contra el terrorismo.

Indonesia continúa promoviendo la cooperación bilateral y sus esfuerzos de lucha contra el terrorismo con Australia, lo que refleja la intención de Jokowi de perseguir el bilateralismo en un intento por aumentar los beneficios para Indonesia (Poole, 2015). Sin embargo, Australia ha expresado su preocupación por el plan de Indonesia de librar a Abu Bakar Basyir de su arresto domiciliario. Basyir es considerado el autor intelectual del atentado de Bali que mató a cientos de australianos, y es el emir de Jemaah Islamyiah. Tiene 80 años y su salud está disminuyendo. En septiembre, el embajador estadounidense Nathan A. Sales firmó un memorando de entendimiento con el jefe de la agencia antiterrorista de 
Indonesia, Suhardi Alius, en el que promete aumentar la cooperación bilateral y el intercambio de información (Dianti, 2018).

\section{DESASTRES NATURALES}

Una serie de terremotos sacudieron la isla Lombok entre el 29 de julio y el 19 de agosto, desde una réplica de magnitud 5.4 hasta dos temblores de magnitud 6.9. Casi 550 personas murieron y más de 1800 resultaron heridas. Lombok se encuentra al este de la isla de Bali y tiene una industria turística próspera, aunque no se informó que murieran turistas en los terremotos, aunque sí se mencionaron problemas generalizados que incluyen a personas que quedaron sin hogar, turistas varados fuera de los hoteles dañados, y un éxodo masivo de personas de la isla que causó problemas en el transporte. Las fotos y el video del terremoto, así como de sus consecuencias, se propagaron rápidamente mediante las redes sociales y otros canales. Dichos terremotos dieron por resultado cientos de millones de dólares en daños a la isla, aunque los residentes de Lombok también se preocuparon por los efectos a largo plazo de más terremotos, por temor a que la industria turística se vea perjudicada ya que la gente teme ahora visitar la isla.

A los terremotos de Lombok les siguieron, el 28 de septiembre, otros en el centro de Sulawesi de hasta 6.1 grados en la escala de Richter, y el principal, de 7.5 grados (se han reportado cientos de réplicas de hasta 5.0 puntos), el cual causó la licuefacción del suelo y destrucción generalizada, y fue seguido por un tsunami, del que se informó que fue de al menos dos metros.

El terremoto y el tsunami causaron devastación y muerte generalizadas; se cree que al menos 70000 edificios fueron destruidos. No obstante, al momento de escribir esto se menciona que al menos 1550 personas perecieron (los rescatistas aún están buscando víctimas). Los indonesios criticaron el sistema de respuesta de emergencia, que falló debido a la caída de las redes celulares. Sólo cinco días después el volcán Supotan de Sulawesi entró en erupción, y aunque el epicentro del terremoto y el volcán están separados por cientos de kilómetros, los expertos no han verificado si existe un vínculo entre ambos.

El Anak Krakatau, que se localiza entre Sumatra y Java, también ha estado en erupción. Este volcán reside en la caldera que dejó Krakatau ("anak" significa "hijo de”), cuya 
cataclísmica erupción de 1883 afectó el clima mundial durante cinco años. Anak Krakatau está regularmente activo, y se cree que su última erupción no está vinculada a los desastres en Sulawesi. Aún así, en términos de desastres naturales en Indonesia, éste parece ser un año particularmente malo.

\section{LA ANSEA Y LAS RELACIONES EXTERIORES}

Los estados miembros de la ANSEA inicialmente desconfiaron de los pronunciamientos y acciones de Jokowi sobre la soberanía de Indonesia, y de sus críticas a las políticas de SBY que él consideraba elitistas e internacionalistas. Los socios de la ANSEA temían que Indonesia se replegara y se cumplieran las promesas de Jokowi de poner al pueblo indonesio en primer lugar, a la par de la posibilidad de un enfoque más complejo de los problemas de soberanía y seguridad marítima. ¿Acaso han sido confirmados estos temores?

La respuesta más simple es no. A pesar del énfasis de Jokowi en el bilateralismo, y de las primeras declaraciones de la administración sobre la ANSEA, Indonesia parece continuar confiando en esta asociación, no obstante reconocer sus deficiencias. Por ejemplo, al reconocer las diferencias internas entre los reclamantes de la ANSEA en las disputas por el Mar del Sur de China, Jokowi ha argumentado que éstas deben resolverse primero antes de presentar un frente unido de la asociación hacia China. En lugar de alejarse de la ANSEA, Jokowi ha señalado sus limitaciones como organización, lo cual no es lo mismo que expresar un deseo de debilitarse o retirarse de la organización, como expresaron algunos críticos iniciales. Jokowi expresó también su deseo de que la ANSEA desempeñe un papel en la continua crisis de Rohingya en Myanmar, aunque dada la incapacidad de la asociación para interferir en los asuntos internos de los estados miembros, esto debería ser por invitación de Myanmar, algo que simplemente no es realista. También ha prometido a sus vecinos que Indonesia continuará sus esfuerzos para reducir la neblina transfronteriza de los incendios forestales.

Al evaluar la administración de Jokowi y su relación con la señalada asociación, parece que Indonesia continuará apoyando a la organización y desempeñando un papel en su liderazgo a pesar de sus primeras declaraciones iniciales, declaraciones que pretendían obtener apoyo entre sus partidarios nacionales. Los temores de una retirada indonesia fueron mal entendidos o exagerados, aunque quizá sus críticas a la ANSEA lleven a la organización 
a considerar sus limitaciones de manera más realista o a cambiar sus estrategias para enfrentar a una China asertiva.

Indonesia también aumentará su perfil internacional fuera de la asociación, tras ganar un puesto en el Consejo de Seguridad de las Naciones Unidas luego de derrotar a Maldivas. Se unirá a Alemania, Sudáfrica, Bélgica y República Dominicana.

\section{JUEGOS ASIÁTICOS}

Indonesia fue sede de los Juegos Asiáticos 2018 que tuvieron lugar en su capital, Yakarta, así como en la capital del sur de Sumatra, Palembang. Aunque hubo preocupación por el tráfico y la contaminación, así como por el terrorismo, debido a los recientes ataques en Java, los eventos se desarrollaron sólo con algunos incidentes relativamente menores. Indonesia ocupó el cuarto lugar en el tablero de medallas, después de China, Japón y Corea del Sur. Corea del Norte y Corea del Sur marcharon juntos en la ceremonia de apertura y compitieron en algunos eventos como un equipo unificado.

Aparte de la mencionada represión policial contra el crimen, los juegos tuvieron las típicas pequeñas controversias en torno a eventos de esa naturaleza, como acusaciones de parcialidad por parte de los árbitros, y un caso de dopaje. Pero quizá fueron los eventos en Yakarta los que condujeron a donde se podían encontrar las controversias más importantes. A principios de julio se instaló una red de nailon para cubrir el severamente contaminado río Sentiong, conocido coloquialmente como un elemento kali o río negro, para protegerlo de la vista y para disfrazar su olor en la cercana aldea de los atletas. Los críticos se preguntaron por qué el gasto de 580 millones de rupias no se destinó para limpiar el río.

A finales de mayo, aparecieron árboles de plástico en toda Yakarta, que a veces fueron colocados de manera inconveniente en medio del tránsito peatonal. El hecho fue recibido con gran burla casi inmediatamente que aumentaron las quejas de los peatones, y los árboles finalmente fueron removidos. Las críticas en línea acerca del costo de los árboles se extendieron por algunos días, y los funcionarios de la administración del gobernador de Yakarta, Anies Baswedan, se apresuraron a esquivar la culpabilidad, incluida culpar a la administración anterior, de Ahok. 


\section{TENSIONES CONTINUAS EN PAPÚA NueVA GUINEA}

Quedan aún tensiones en las provincias de Papúa y Papúa Occidental. La región se integró oficialmente en 1969 después de varios años de presencia indonesia mediante una "Acta de libre elección" simulada que fue supervisada por las Naciones Unidas. 1200 papuanos que fueron seleccionados por Indonesia votaron a favor de la ley, y aquellos que no expresaron su apoyo a la integración de la región con Indonesia fueron torturados o asesinados. Una insurgencia separatista, liderada por Organisasi Papua Merdeka (Organización de Papúa Libre: OPM) ha luchado contra Indonesia desde su incorporación con una intensidad que ha variado a lo largo de los años, y la región sigue siendo una de las más pobres de Indonesia, con pésimos niveles de desarrollo.

Parte de la insatisfacción entre los papúes se debe a la mina Grasberg, la mina de oro a cielo abierto más grande del mundo, cerca de Timika. La multinacional estadounidense Freeport McMoRan dirigió la operación, pagando a militares y policías de Indonesia como guardias privados. Sin embargo, esta empresa ha sido acusada de destrucción ambiental y de violaciones a los derechos humanos y laborales, y es frecuentemente blanco de protestas e incluso de ataques. Después de años de disputa sobre la propiedad de la mina, Freeport McMoRan firmó un acuerdo en julio con el gobierno indonesio en el que cedió más de $40 \%$ de su participación en Grasberg, hecho que lo convirtió en socio minoritario, efectivo a partir de 2022.

\section{CONCLUSIÓN}

Finalmente, aunque las elecciones regionales de 2018 mostraron una señal inicial de apoyo a Jokowi, la verdadera prueba será cómo se desarrollará la campaña presidencial de 2019. La democratización es un proceso, y aunque Indonesia parece seguir progresando en muchos aspectos, los críticos también apuntan a indicadores que parecen regresivos. En un contexto global, con el vecino filipino Rodrigo Duterte burlando el estado de derecho y el presidente Donald Trump apoyando el liberalismo en todo el mundo, no debería sorprender que los políticos en Indonesia también hayan sido arrastrados hacia la derecha. Con algunas políticas que ya reflejan esto, como la orden de "disparar a la vista" en Yakarta durante los Juegos Asiáticos, la pregunta es si este giro hacia la derecha continuará después de la elección. 
La elección de Prabowo cimentaría este giro, aunque también podría abrir a Indonesia hacia las críticas de las comunidades regionales y globales. El aniversario de reformasi atrajo la atención de los indonesios sobre el progreso que han logrado, pero también sobre los perpetradores que permanecen impunes. Haciendo eco de los recientes llamamientos para revisar los asesinatos en masa de 1965, también nos recuerda que aunque Indonesia ha llegado muy lejos, en términos de consolidación de su democracia todavía hay mucho por hacer.

\section{REFERENCIAS CONSULTADAS}

"10 anggota TNI jadi tersangka kasus La Gode", (2018), Koran Tempo, 4 de enero. Recuperado de: https://koran.tempo.co/read/425881/10-anggota-tni-jadi-tersangkakasus-la-gode

Amar (2018), "Kasus tewasnya La Gode, 11 anggota TNI disidang de pengadilan militer", Kumparan.com, 9 de mayo. Recuperado de: https://kumparan.com/ambonnesia/11anggota-tni-pelaku-pembunuhan-warga-ternate-disidang-di-peradilan-militer-ambon

Azali, Kathleen (2017), "Fake News and Increased Persecution in Indonesia", Perspective, 7 de agosto. Recuperado de: https://www.iseas.edu.sg/images/pdf/ISEAS_Perspective_2017_61.pdf

Dianti, Tria (2018), "US Counter-Terror Envoy Stresses Cooperation with Southeast Asia", Benar News, 14 de septiembre. Recuperado de: https://www.benarnews.org/english/news/indonesian/US-envoy-Nathan-Sales09142018142616.html

Djailani, Irwan (2017), "Ribuan warga dukung kematian La Gode di Lede", Radio Republik Indonesia, 24 de noviembre. Recuperado de: http://rri.co.id/ternate/post/berita/460542/daerah/ribuan_warga_dukung_kematian_la_ gode_di_lede.html

Epa, Konradus (2018), "Indonesia Gets New Isamic [sic] Anti-Terror Agency", UCA News, 5 de octubre. Recuperado de: https://www.ucanews.com/news/indonesia-gets-newisamic-anti-terror-agency/83549 
(2018), "FPI Leaders Turned Back by Hundreds of Dayak Youth Protesters in N. Kalimantan, Cancel plans to Open Regional Chapter", Coconuts Jakarta, 16 de julio. Recuperado de: https://coconuts.co/jakarta/news/fpi-leaders-turned-back-hundreds-dayak-youthprotesters-n-kalimantan-cancel-plans-open-regional-chapter/

(2018), “Gov't Proposes to Remove 'Same Sex' From Bill on Fornication”, The Jakarta Post, 31 de mayo. Recuperado de: http://www.thejakartapost.com/news/2018/05/31/indonesia-to-remove-same-sexfrom-law-on-fornication.html

(2018), "Indonesian Islamists Crash Child's Party in Brothel Hunt", The Straits Times, 22 de enero. Recuperado de: https://www.straitstimes.com/asia/se-asia/indonesian-islamistscrash-childs-party-in-brothel-hunt

(2018), "Indonesian Police Told to Shoot on Sight for Street Crimes", The Straits Times, 4 de julio. Recuperado de: https://www.straitstimes.com/asia/se-asia/indonesian-policetold-to-shoot-on-sight-for-street-crimes

Jones, Sidney (2018), "How ISIS has Changed Terrorism in Indonesia", New York Times, 22 de mayo. Recuperado de: https://www.nytimes.com/2018/05/22/opinion/isisterrorism-indonesia-women.html

Kenawas, Yoes C. (2018), "Twenty Years After Suharto: Dynastic Politics and Signs of Subnational Authoritarianism", Kyoto Review of Southeast Asia, 24. Recuperado de: https://kyotoreview.org/issue-24/twenty-years-after-suharto-dynastic-politics-andsigns-of-subnational-authoritarianism/

Kine, Philem (2018), "Jakarta Police 'Shoot to Kill’ Order may Foster Summary Executions”, Human Rights Watch, 6 de julio. Recuperado de: https://www.hrw.org/news/2018/07/06/jakarta-police-shoot-kill-order-may-fostersummary-executions

Kurnia, Dadang y Bambang Noroyono (2018), "Bola Panas 'Lima Parpol Pundukung' LGBT”, Republika, 21 de enero. Recuperado de: https://www.republika.co.id/berita/nasional/news-analysis/18/01/21/p2va4y440-bolapanas-lima-parpol-pendukung-lgbt 
Lamb, Kate (2018), "Indonesian Police Kill Dozens in Asian Games "Clean-Up", The Guardian, 17 de agosto. Recuperado de: https://www.theguardian.com/world/2018/aug/17/indonesian-police-kill-dozens-inasian-games-clean-up

Lamb, Kate (2018), ““A Vigilante State’: Aceh's Citizens Take Sharia Law into their Own Hands", The Guardian, 23 de abril. Recuperado de: https://www.theguardian.com/world/2018/apr/23/a-vigilante-state-acehs-citizenstake-sharia-law-into-their-own-hands

(2018), "Misinformation, Ratna the Hoaxer, and 1965", Indonesia at Melbourne, 8 de octubre. Recuperado de: http://indonesiaatmelbourne.unimelb.edu.au/fake-news-ratna-thehoaxer-and-1965/

(2018), "Nearly 50 Arrested in Jakarta under New Laws that Criminalize Terrorist Sympathizers: National Police Chief', Coconuts Jakarta, 17 de julio. Recuperado de: https://coconuts.co/jakarta/news/50-arrested-jakarta-new-laws-criminalize-terroristsympathizers-national-police-chief/

Pepinsky, Thomas (2017), "Voting Against Disorder", Journal of Democracy, 28(2), pp. 120-131, abril.

Poole, Avery (2015), "Is Jokowi Turning his Back on ASEAn?", The Diplomat, 7 de septiembre. Recuperado de: https://thediplomat.com/2015/09/is-jokowi-turning-hisback-on-asean/

Puspitasari, Maya Ayu, Maulidar, Indri y Efri R. (2018), "Posisi Politik Jokowi Kian Kuat", Koran Tempo, 1, 29 de junio.

Salna, Karlis (2018), "Suharto-Era Indonesian Generals Signal Alliance to Fight Jokowi”, Bloomberg News, 25 de julio. Recuperado de: https://www.bloomberg.com/news/articles/2018-07-25/suharto-era-indonesiangenerals-signal-alliance-to-fight-jokowi

Santoso, Audrey (2018), "Lihat Video AKBP Yusuf Tending ibu-ibu, KAPOLRI marah besar", Detik News, 13 de julio. Recuperado de: https://news.detik.com/berita/4112647/lihatvideo-akbp-yusuf-tendang-ibu-ibu-kapolri-marah-besar 
Siddharta, Amanda (2018), "Virginity Tests put Indonesian Women Off Military Service; Often Performed by Men, they are Seen as Degrading”, The South China Morning Post, 18 de agosto. Recuperado de: https://www.scmp.com/lifestyle/article/2160023/virginity-tests-put-indonesianwomen-military-service-often-performed-men

Widianto, Stanley (2018), "Indonesia is About to Outlaw Homosexual Sex. Can We Stop It?", The Guardian, 13 de febrero. Recuperado de: https://www.theguardian.com/commentisfree/2018/feb/14/indonesia-is-about-tooutlaw-homosexual-sex-can-we-stop-it

Wiwoho, Bimo (2018), "Widod's Ruling Party Seeking Support from Hardline FPI Leader Rizieq Shihab", CNN Indonesia, 21 de agosto. Recuperado de: http://asia-pacificsolidarity.net/southeastasia/indonesia/indoleft/2018/cnn_widodosrulingpartyseeking _ 210818.htm

Woodward, Mark, Mariani Yahya, Inaya Rohmaniyah, Diana Murtaugh Coleman, Chris Lundry y Ali Amin (2014), "The Islamic Defenders Front: Demonization, Violence, and the State in Indonesia", Contemporary Islam, 8(2), pp. 153-171, mayo.

Woodward, Mark (2018), "Sectarianism, Culture and Politics", Inside Indonesia, 24 de enero. Recuperado de: http://www.insideindonesia.org/sectarianism-culture-and-politics Yuniar, Resty Woro y Jeffrey Hutton (2018), “Indonesia's Reformasi Activists Were Burned, Beaten, Electrocuted-and they Still Fear for their Country", The South China Morning Post, 20 de mayo. Recuperado de: https://www.scmp.com/weekasia/politics/article/2146839/indonesias-reformasi-activists-were-burned-beatenelectrocuted 